\title{
Recipe for success in international specialist meetings
}

\author{
J Alexander-Williams, L P Fielding, S Goldberg, R H Grace
}

The organisation of international meetings is a growth industry. Throughout the world individual organisations and cities compete, often ruthlessly, for the privilege of hosting such meetings. International specialist meetings provide a forum for the widest possible exchange of ideas on a narrow subject, ideas that may stimulate constructive criticism and mutual benefits among experts who might not otherwise meet. In this paper we propose directions for a successful specialist meeting and, in particular, introduce new ideas for communication. Our thoughts are based on extensive experience of attending such meetings, both good and bad, informative and boring, and, more immediately, on the experience gained by two of us (JAW and RHG) in organising a medium sized international meeting with 420 registrants in Birmingham in 1989 and by the other two (LPF and SG) in assessing it critically. We are aware that our experience and recommendations are relevant only for meetings of a similar size. Larger meetings attracting 1000 or more registrants have different rules, but we think that many of the principles defined here are still pertinent. We do not claim to have found the answers; all that we have been able to do is understand some of the questions.

We began the study by trying to define the purpose of an international specialist meeting; we then attempted to put these ideas into practice by running a meeting; and, finally, we held a postmortem examination to find out where the meeting had succeeded and where it had failed to achieve the objectives as defined in the purpose. Whatever the specialty the aims of international meetings are similar and the problems are the same; our experience relates particularly to the specialty of coloproctology.

\section{Purpose}

Education is the main purpose of any scientific specialist meeting. Communication is needed to achieve this. Participants must have the opportunity to be exposed to new ideas and to question current conventional wisdom. Verbal communication among participants allows them the opportunity to question work that otherwise would be presented only in print. The probability of direct questioning in public should concentrate the speaker's mind and ensure honesty in presentation of data. Vulnerable data, when challenged, will be seen to be frail. It is at such meetings that "next season's" men will appear and thereby have an opportunity to enhance their career. It is by observing the performance in public of young research workers that future panellists are selected and lecturers overviewed. Conversations in corridors at such meetings often determine the direction of the career development of talented young trainees; this must be the lifeblood of the advancement of the specialty as much as that of the specialists.

\section{Finance}

Many meetings are financed largely from the advertising revenue of pharmaceutical, equipment, or service industries, and this has the danger of injecting commercial bias and may not be a permanent feature of future meetings. The financing of any international meeting depends partly on the registration fees of the participants. The more delegates attending, therefore, the more financially stable is the meeting and the more can be spent on the organisation. The travel budgets of many hospitals, institutions, and universities are limited, and financial support to attend the meeting is usually restricted to those who present data. Therefore, when selecting proferred papers there is an immediate dilemma between quality and quantity. There is conflict between the need to encourage the maximum number of delegates to attend to ensure financial stability and maintaining a high quality of individual presentation. We believe that quantity and quality are compatible only if all the presentations are subject to public criticism; no presentation should be hidden in the meeting merely to encourage attendance. We disapprove of the practice of having papers accepted under the euphemism "read by title" or having posters that are not subjected to criticism. Since we started to write this paper three of us (JAW, LPF, and SG) have participated in a highly successful world congress of gastroenterology in Sydney, where there were over 6000 registrants. With that number it was clearly not possible to have every delegate's proferred work subjected to peer review as open criticism, and most delegates could have their attendance sponsored only if their work was accepted. The pragmatic solution was to publish those abstracts that were accepted but not selected for open discussion as a podium or poster presentation. They were published in a book the size of a respectable telephone directory but were never discussed. Delegates were invited to display enlarged versions of their abstract as posters that were not manned or discussed. This compromise helps delegates to obtain sponsorship but is difficult to justify intellectually as almost all abstracts are accepted and none criticised. Is there no other way? Perhaps delegates should be sponsored only if they guarantee to pose an intelligent question in discussion time. Meetings with a reputation for quality will always attract delegates; such quality meetings held in an attractive venue will guarantee good attendance.

\section{Use of time}

All meetings have a time limit. The programme is planned within this limit, remembering that a plenary lecture of half an hour takes up the same time as three podium presentations or 10 poster discussions. Two parallel sessions allow twice as many presentations, but this has the disadvantage that participants cannot attend all presentations.

\section{Methods of communication}

Several of the ways of presenting information at meetings are discussed below.

\section{STATE OF THE ART LECTURES}

The state of the art lecture usually honours a distinguished colleague or a great innovator. The speaker must have something to say, know the subject, and speak well; without these three principles there is 


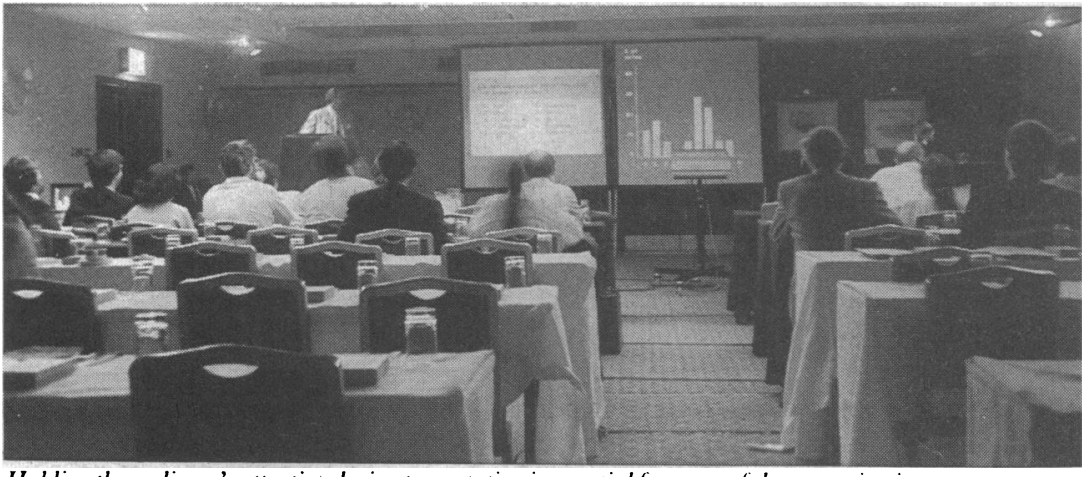

Holding the audience's attention during presentation is essential for success/ul communication

no place for a formal lecture taking up so much precious time. We suggest that such lectures should be limited to 20 minutes.

ROUNI) TABIL OR PANEL DISCUSSION

The round table or pancl discussion usually takes between one and two hours, with invited experts discussing a particular theme. We believe 90 minutes to be optimum and two hours too long. Members of the panel should be invited because of their particular expertise and their skill in argument. Sadly, they are sometimes asked because they are known to be eccentric or simply because of their seniority. The objective of such a panel should be to give an opportunity for divergent views to be aired and to allow the audience to hear experts expounding their point of view; in particular, arguing the merits of different opinions. The principal problem with such a round table discussion is the variable quality of the experts and the limitations of their skills of communication. It is often difficult to keep senior experts to their allotted time or make them stick to the theme that is being developed. Brilliant panel discussions usually depend on the personality and communication skills of the moderator. In our experience international panels often fail to make the desired impact because members simply present a succession of expert papers, which are inexpertly delivered, on a succession of loosely related subjects. The presenters often overrun their time and thereby preclude useful discussion.

Pancl discussion should be constructed so that opposing views are aired with ample time for inter panel and audience participation. The moderator must work hard well before the meeting, planning details and giving precise instructions to the panellists. The panellists should know the details of their copanellists presentations, particularly their views on any points of controversy. Arguments add spice to a panel, but panellists perform better in arguments if they are forewarned of the controversy. We believe that the best panels are those in which the moderator asks the panel members to answer some previously circulated questions requiring short answers. Also, the moderator should allow the audience time to question and comment. This prearranged format requires meticulous preparation, with the chairman and the panel members being aware which of the questions is their principal responsibility. It is often difficult to predict accurately the timing in such a panel. The chairman should therefore leave the less important questions to the end so that he or she can stop and sum up before the scheduled closing time without having to rush at the end. Pancls should end on time with the audience thirsting for more.

ORIGINAI. PAI'IERS

Podium presentation has always been the mainstay of any mecting. The organising committec has to decide how long should be allowed for individual presentations and how best to allow audience partici- pation. In the past some meetings have allowed up to 20 minutes for each presentation, but recently 10 minutes has come to be accepted as the standard. With the expertise of presentation now expected this could possibly be reduced to eight minutes; five minutes for presentation and three for discussion. Presenters should not spend the first minute or two congratulating the committee on their wisdom in selecting their paper nor waste time with pompous presentations or facetious introductions. A short time limit should prevent insensitive enthusiasts presenting their life's work illustrated by a flurry of slides.

There is a tendency to group presentations on a similar subject together. This has the advantage of allowing the audience to concentrate on their subject ofinterest without having to move from hall to hall. There is a disadvantage if the chairman groups papers together with all the discussion at the end. This may have a negative effect on subsequent discussion, with the earlier papers often being ignored. All presenters should be given the courtesy of receiving comments and questions from the audience. A good chairman will try to leave some time for general discussion at the end of each theme.

The mechanism for audience participation needs careful consideration. The dilemma facing the chairman is how to organise discussion from the floor. The solution has tended to be different on either side of the Atlantic. In the United Kingdom it has been usual to allow the audience free access to a microphone to allow them to criticise or question the speaker. This sometimes results in lame discussion from an audience reticent to expose their limitations of knowledge in public. When it works well it allows genuine critique and results in contributions that are of value both to the speaker and to the audience. In the United States and some parts of Europe there has been a tendency for such freedom of audience participation to be abused by some members of the audience who, lacking inhibition and, often, sensitivity, try to monopolise the discussion by delivering their own supplementary, loosely related paper, sometimes even trying to illustrate it with slides. In the United States the countermeasure to this abuse of discussion time has been to allow questions only in writing. These are selected and then posed by the chairman. This usually limits discussion to brief questions because few chairmen have the time, ability, or inclination to digest and reiterate complex contradictory statements. A glib one line statement or question is always likely to be the moderator's choice Attempts by the chairman to call for comments and questions from named, forwarned discussants is often contrived and usually obvious. We believe that the United Kingdom system of allowing questions and comments from the floor ensures the best discussion; the chairman must deal firmly with any abuse of this privilege. Discussion from the floor requires good microphone back up. Roving microphones may be needed if there is theatre style seating. We believe it best, however, to have discussants line up at microphones in the aisles as this alerts the chairman to the potential number and eminence of prospective questioners.

\section{Poster presentations}

Usually, the best abstracts are accepted for podium presentation and the next highest scoring abstracts for poster presentation. We believe that it is better to select for posters those data that are best displayed in simple graphic form. It is often difficult, however, for the selection panel to make such decisions on the submitted abstracts, and it is difficult for authors to think of their data as poster material.

Decisions have to be made as to how many posters to accept and for how long should they be displayed to 
allow sufficient time for the audience to view them. We believe that it is very important to ensure that posters are adequately discussed. The numbers to be accepted may be determined by the space available for display. In single specialty meetings, where most of the participants will be interested in all the subjects, they can be discouraged by the prospect of viewing too many posters in too short a time. As experienced poster reviewers, we find that our limit is about 30 posters an hour. The audience must have sufficient time to view the posters, but they can partake of refreshment, even a finger buffet, while doing so.

The traditional format for poster discussion in the United Kingdom is for the author to stand by the poster at set times during the meeting with the audience free to visit and discuss. In America it is more common for invited chairmen to take small groups around the posters and discuss them with the presenters. If the group is of more than 12 people it is often difficult to hear and discuss, and many groups discussing at once sound like playtime at school.

We thought that neither of these forms was effective, and at our international colorectal meeting in Birmingham in 1989 we arranged that time should be set aside for poster discussion with the whole audience. A chairman assisted by two moderators ran the meeting, with each presenter in turn being allowed two slides projected side by side. The first slide was an overall slide of the whole poster (as a reminder to the audience) and the second presented the conclusions. The presenter stood on the podium and simply responded when questioned by the audience. The role of the moderators was to lead the discussion by criticising or congratulating not only the content of the poster but also the form of presentation. With this format we were able to discuss 20 to 30 posters in an hour and to ensure that no presentation was listed on the programme without being subjected to peer review in open forum.

\section{AUDIENCE PARTICIPATION}

One of the shortcomings of large international gatherings is the lack of opportunity for the audience to participate actively in discussion and exchange of opinions. This is particularly frustrating in specialist medical meetings, where most of the audience are fully trained clinicians. Modern technology in the form of an interactive keypad system, connected to a computer and videographic display, enables the audience to participate and respond to questions and indicate whether or not they agree with the principal speakers. We used this system at our colorectal meeting to involve the audience and a panel of experts in making decisions about the investigation and treatment of a series of patients with complicated Crohn's disease. Firstly, the case history was presented, the audience were then given the choice of different investigations that they could order, and later they were given a choice of treatment options. When they had indicated their answer to each question by pressing the appropriate key on the keypad the international panel of experts were asked to respond. After the experts had committed themselves the video projector displayed the percentage answers from the audience. Then panel members holding different opinions from the audience argued their view or said why they thought the audience was wrong. Whenever there was a particularly compelling argument the vote was taken again to see whether the audience had been persuaded to change their views.

The interactive keypad system ensures a lively discussion and, if it is run well, holds the audience's attention. It is expensive, however, because keypads have to be installed at each seat or desk and connected to a computer. Much preparation is required in carefully choosing suitable questions and formulating the questions to fit the format of a multiple choice examination question. We believe that this is a promising method of communication, particularly at the international meeting, when answers from different national groups can be compared by the computer. The question session should, however, last only as long as the audience's interest can be maintained.

\section{BREAKFAST SESSIONS}

In most meetings there is rarely time to discuss difficult or interesting clinical problems. This need can be met by what is sometimes called a breakfast or "meet the experts" session. Discussion takes place during breakfast at tables 10 to $16 ; 10$ is optimum as it allows everyone to hear and participate. Each table has a chairman and cochairman, who either introduce discussion on clinical problems or respond to questions from the audience, who raise their own problems. Our organisation had the chairmen remaining at the same table each morning of the meeting while the audience moved to a different table each day. Usually this is a popular session with both chairmen and participants.

\section{Other considerations}

There are many other important activities that need careful consideration and planning, including the social programme, accommodation, transportation, committee and official society business. Not least, the overall organisers have to consider the extent of the burden that it is fair to inflict on local organisers and how careful planning and accumulated experience can ease the burden. These subjects are no less importan than the scientific sessions in the recipe for a successful meeting.

\section{ANY QUESTIONS}

Is there a risk that mammography in a patient with clinically diagnosed breast cancer will disseminate malignant cells?

No evidence has been reported that mammography has caused dissemination of malignant cells in any patient, although it may be a theoretical possibility. For dissemination to occur, however, there would have to be vascular invasion by the tumour at the time of the mammogram, an event which in itself would be likely to be associated with dissemination. Dissemination of cells is only one part of a complex multifactorial process that may or may not lead to the formation of marked metastatic deposits.

Any theoretical risk has to be balanced against the proved benefits. The presence in the affected breast of additional subclinical foci, or of extensive coexistent ductal carcinoma in situ may be detected only by mammography, findings that would make local excision of the cancer inappropriate. Evidence that the radiological extent and measurement of the distance between tumour and nipple are two excellent preoperative predictors of subsequent local recurrence means that these factors should also be considered when contemplating local excision.'

Where mastectomy has been decided on as the primary treatment the reasons for mammography stated above do not apply but in such patients mammography of the contralateral breast should be done. This is in order to identify these $3 \%$ of women who have a clinically occult but mammographically detectable cancer in the opposite breast. - E J ROEBUCK, consultant radiologist, Nottingham

1 Roebuck EJ. Clinical radiology of the breast. Oxford: Heinemann, 1990:204. 